\title{
Tissue-Level Cardiac Electrophysiology Studied in Murine Myocardium Using a Microelectrode Array: Autonomic and Thermal Modulation
}

\author{
Jem D. Lane ${ }^{1} \cdot$ David Montaigne $^{1,2,3,4,5,6} \cdot$ Andrew Tinker $^{1}{ }_{(\mathbb{C}}$
}

Received: 4 January 2017 / Accepted: 25 July 2017/Published online: 1 August 2017

(c) The Author(s) 2017. This article is an open access publication

\begin{abstract}
Cardiac electrophysiology is regulated by the autonomic nervous system, and this has both pathophysiological, and possibly therapeutic importance. Furthermore, chamber differences in electrophysiology exist between atria and ventricles, yet there have been few direct comparisons. There is substantial literature on ion channel modulation at the single-cell level but less work on how this affects tissue-level parameters. We used a microelectrode array system to explore these issues using murine atrial and ventricular tissue slices. Activation time, conduction velocity and repolarisation were measured, and their modulation by temperature and pharmacological autonomic agonists were assessed. The system recorded reliable measurements under control conditions in the absence of drug/thermal challenge, and significant baseline differences were found in chamber electrophysiology. The sodium channel blocker mexiletine, produced large magnitude changes in all three measured parameters. Carbachol and isoprenaline induced differing effects in atria and ventricles, whereas temperature produced similar effects on activation and repolarisation.
\end{abstract}

Andrew Tinker

a.tinker@qmul.ac.uk

1 William Harvey Heart Centre, Barts \& The London School of Medicine and Dentistry, London, UK

2 Department of Cardiac Functional Investigations, CHU Lille, 59000 Lille, France

3 Univ. Lille, 59000 Lille, France

4 Inserm, UMR 1011, 59000 Lille, France

5 Institut Pasteur de Lille, Lille, France

6 European Genomic Institute for Diabetes (E.G.I.D.), FR 3508, 59000 Lille, France
Keywords Autonomic regulation · Cardiac electrophysiology $\cdot$ Temperature

\section{Introduction}

Great progress has been made in our understanding of cardiac electrophysiology over the last century (Janse and Rosen 2006). The advent of patch clamping allowed the study of single cardiomyocytes and led to the isolation of specific currents underlying the cardiac action potential (Coraboeuf and Weidmann 1949; Ling and Gerard 1949). This, combined with the cloning of ion channel subunits, led to an explosion of knowledge about channel regulation often in exquisite molecular detail. However, there has been comparatively less study of the electrophysiological properties of intact tissues and the hormonal and thermal regulation of these. The key difference compared to singlecell systems is that intercellular connections are preserved that are critical in regulating the three key electrophysiological parameters-activation, repolarisation and conduction. Modulation of these occurs physiologically via the autonomic nervous system. Sympathovagal imbalance can perturb them, however, creating conditions favourable to arrhythmogenesis (Shen and Zipes 2014). And while little attention has been paid to thermal modulation, its importance is illustrated by the role of fever in triggering arrhythmias in Brugada syndrome, for example.

Microelectrode arrays (MEA) have been used to study cardiac tissue slices for just over a decade (Pillekamp et al. 2005). This system offers the advantages of being able to assess drug effects in tissue, as opposed to single cells. Multiple slices from the same heart can be assessed, maximising use of the animal and possibly reducing variability between slices. Few studies have directly compared 
electrophysiological properties in atria and ventricles (Giles and Imaizumi 1988). Important differences may exist which could be amenable to exploitation with drugs and if adapted robustly to the mouse may be suitable for examining genetically modified strains. We used the MEA to evaluate the effects of autonomic modulators and temperature on ex vivo murine cardiac atrial and ventricular tissue slices, and to compare the responses in preparations from each chamber.

\section{Methods}

\section{Experimental Animals}

Mice were housed in individually ventilated cages, with free access to standard rodent chow and water, with 12-h day-night cycles, and in accordance with British Home Office animal welfare guidelines (PPL 70/7665). All mice were on a $129 \mathrm{~Sv}$ background; males and females were used. At the time of study, they were 8-12 weeks old, weight over $20 \mathrm{~g}$.

\section{Buffer Solutions}

The following modified Krebs-Henseleit buffer (hereafter termed 'Krebs') master solution was made up prior to slice preparation on the day of procedure (molecular concentration): $\mathrm{NaCl}(118 \mathrm{mM}), \mathrm{KCl}(3.8 \mathrm{mM}), \mathrm{MgSO}_{4} \cdot 7 \mathrm{H}_{2} \mathrm{O}$ (1.19 mM), $\mathrm{NaHCO}_{3} \quad(25 \mathrm{mM}), \mathrm{KH}_{2} \mathrm{PO}_{4} \quad(1.19 \mathrm{mM})$, D-glucose $(5 \mathrm{mM})$ and sodium pyruvate $(2 \mathrm{mM})$ were dissolved in $1 \mathrm{~L}$ of distilled water (all from SigmaAldrich). This 'Calcium-free Krebs' solution was used to produce the following modified Krebs solution, with addition of appropriate amounts of $\mathrm{CaCl}_{2}, \mathrm{KCl}$ and 2,3-butanedione monoxime (BDM) (Sigma-Aldrich): Normal Krebs $\left(\mathrm{Ca}^{2+} 1.4 \mathrm{mM}, \mathrm{K}^{+} 5 \mathrm{mM}\right)$ at $4{ }^{\circ} \mathrm{C}$, PerfusionSlicing Krebs $\left(\mathrm{Ca}^{2+} 0.6 \mathrm{mM}, \mathrm{K}^{+} 15 \mathrm{mM}\right.$, BDM (10 mM) at $4{ }^{\circ} \mathrm{C}$, Resting Krebs (same as Perfusion-Slicing Krebs) at $21{ }^{\circ} \mathrm{C}$, Preparation Krebs $\left(\mathrm{Ca}^{2+} 1.4 \mathrm{mM}, \mathrm{K}^{+} 5 \mathrm{mM}\right.$, BDM $10 \mathrm{mM})$ at $21^{\circ} \mathrm{C}$ and Bathing Krebs $\left(\mathrm{Ca}^{2+} 1.4 \mathrm{mM}\right.$, $\left.\mathrm{K}^{+} 5 \mathrm{mM}\right)$ at $37^{\circ} \mathrm{C}$.

\section{Measurement of Myocardial Electrophysiology Using Microelectrode Arrays}

Using a microelectrode array (MEA, Multichannel Systems), we investigated, in ex vivo murine left atrial and ventricular tissue preparations, the effects of temperature and pharmacological agonists on electrophysiological (EP) parameters, i.e., activation time (AT) latency, effective refractory period (ERP) and conduction velocity (CV). Isolated mouse hearts were washed in Normal Krebs, before being mounted on a Langendorff setup and perfused with Perfusion-Slicing Krebs. The heart was transected at the atrioventricular groove, and atrial tissue was transferred directly to the MEA without tissue slicing and perfused with Bathing Krebs solution $\left(37{ }^{\circ} \mathrm{C}\right.$; $95 \%$ oxygen $/ 5 \%$ carbon dioxide).

The left ventricular slices were prepared for slicing in a similar manner to that described previously (Halbach et al. 2006). Briefly, the ventricular base was glued to a cylindrical metal 'coin', and placed in a chamber on the vibratome (Vibrating Microtome 7000-smz2, Campden Instruments Ltd, UK). The chamber was filled with Perfusion-Slicing Krebs at $4{ }^{\circ} \mathrm{C}$, After removal of the apex, three slices of thickness $250 \mu \mathrm{m}$ were cut with slicing settings of frequency $50 \mathrm{~Hz}$, amplitude $1.00 \mathrm{~mm}$, z-deflection $<2 \mu \mathrm{m}$ and advance rate $0.02 \mathrm{~mm} / \mathrm{s}$. This resulted in a slicing plane similar to the 'horizontal transmural' slices described in Bussek et al's paper (Bussek et al. 2009). After each slice was cut, it was transferred to a Falcon tube containing carbogenated (95\% oxygen, 5\% carbon dioxide) Resting Krebs at room temperature. Slices were kept in Resting Krebs for $30 \mathrm{~min}$, after which they were transferred to carbogenated Preparation Krebs also at room temperature.

Left atrial and ventricular electrophysiological parameters were assessed during electrical stimulation using a microelectrode array (MEA) system which allowed noninvasive synchronous multifocal recording of unipolar electrograms (UEGMs), referred to as extracellular field potentials in the literature. The MEA (MEA2100, Multi Channel Systems, Reutlingen, Germany) consists of 60 microelectrodes arranged in an $8 \times 8$ matrix, with a $20-\mu \mathrm{m}$ electrode diameter and an interelectrode distance of $200 \mu \mathrm{m}$. Myocardial samples were positioned in the centre of the MEA dish, held in contact with electrodes by a holder, and continuously superfused with oxygenated Bathing Krebs solution at $37^{\circ} \mathrm{C}$. For ventricular slices, a run-in period of $30 \mathrm{~min}$ was used to allow washout of BDM, and recovery of excitability. During this time, the slice was paced at $1 \mathrm{~Hz}$ for $20 \mathrm{~min}$, then $2 \mathrm{~Hz}$ for 10-15 min, before checking threshold and commencing stimulation at $4 \mathrm{~Hz}$. For the experimental protocol, electrical stimulation (biphasic pulses, twice current threshold, $2 \mathrm{~ms}$ duration, $4 \mathrm{~Hz}$ frequency) was applied via one of the microelectrodes. UEGM data were acquired simultaneously from all 60 microelectrodes with MC Rack (Multi Channel Systems, Reutlingen, Germany). S1-S2 train stimulation with a S1-S1 cycle length of $250 \mathrm{~ms}$ and S1$\mathrm{S} 2$ starting at $140 \mathrm{~ms}$, was used to assess effective refractory period (ERP).

To assess conduction properties, tissue samples were stimulated at $4 \mathrm{~Hz}$, and the UEGMs obtained were processed using LabChart7 (ADInstruments, UK) to define 
local activation time (LAT) based on the most negative derivative of the UEGM (details below). Average conduction velocity $(\mathrm{CV})$ was calculated using interelectrode distance and the difference in activation times, as previously described (Opel et al. 2015) (see below).

Electrophysiological parameters were assessed in a series of experiments: (i) under control conditions in the absence of pharmacological challenge over $35 \mathrm{~min}$; (ii) at baseline and in the presence of the muscarinic agonist carbachol (Alfa Aesar) at concentrations between $1 \mathrm{~nm}$ and $1 \mu \mathrm{m}$, followed by reversal with the receptor antagonist atropine to demonstrate continued responsiveness; (iii) at baseline and in the presence of the non-specific $\beta$-adrenoceptor ( $\beta \mathrm{AR}$ ) agonist isoprenaline (Sigma-Aldrich), at concentrations between $1 \mathrm{~nm}$ and $1 \mu \mathrm{m}$, followed by reversal with the beta adrenoceptor antagonist propranolol to demonstrate continued responsiveness; (iv) during a temperature challenge, at 37,34 and $40{ }^{\circ} \mathrm{C}$, achieved by varying the temperature of Krebs perfusate sequentially; (v) at baseline and in the presence of mexiletine (SigmaAldrich) at 10 and $100 \mu \mathrm{m}$.

\section{Signal Analysis-Calculation of Local Activation Time and Conduction Velocity}

The method of analysis described below assumed linear impulse propagation across the MEA from the reference electrode (the one within $400 \mu \mathrm{m}$ of the stimulating electrode used to define earliest capture; see Fig. 1) to distal electrodes at which activation times were measured. In LabChart, activation time in milliseconds at the reference electrode was measured from the commencement of the stimulus artefact to the maximum negative value on the derivative channel (Fig. 2). The process was repeated for the distal electrode channels to determine their activation times. The distance between the reference electrode and each distal electrode was calculated, and conduction velocity derived from these values. Velocities $<10 \mathrm{~cm} / \mathrm{s}$ or $>150 \mathrm{~cm} / \mathrm{s}$ were excluded from analysis, as they were felt to be outside what could be considered normal.

\section{Statistical Analysis}

All statistical analysis was performed with StataIC 12 (StataCorp LP, USA). Multilevel mixed-effects models were employed to analyse repeated measures data. Statistical significance for was assumed if $p<0.05$ in all circumstances.

\section{Results}

\section{Pooled Baseline Data}

Table 1 summarises the baseline values for left atrial (LA) and left ventricular (LV) ERP, CV and LAT from all experiments, i.e., the measurements prior to any pharmacological or thermal challenge. The value of each

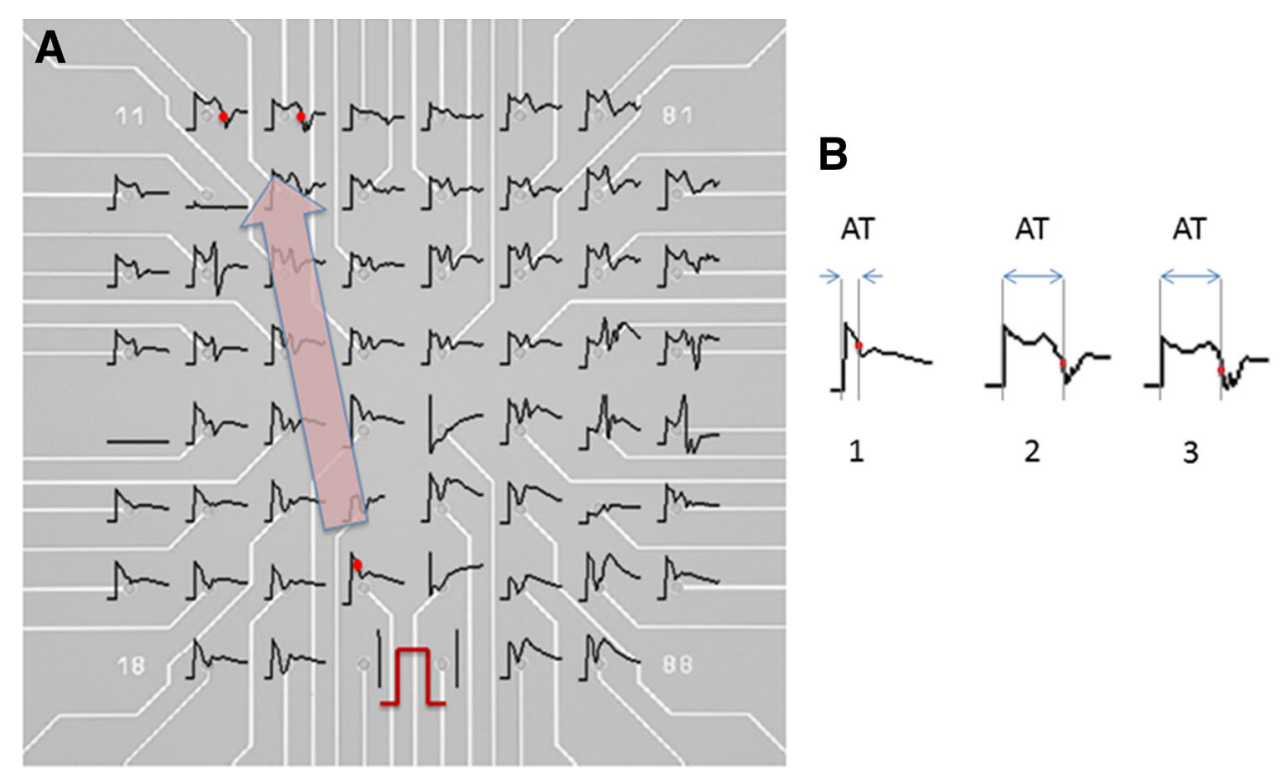

Fig. 1 Representative UEGMs recorded from a ventricular tissue slice using the MEA. a The square wave (red) represents the stimulus at a peripheral electrode. The proximal red dot is the negative deflection on the nearest (reference) electrode to the stimulus. Linear conduction is assumed, and the AT at two distal electrodes on the opposite side of the
MEA is marked by the red dots, with the arrow indicating direction of propagation. b Magnified UEGMs from a. AT is measured from the stimulus onset to the steepest part of the negative deflection, marked by a red dot. (1) was recorded at the reference electrode, and $(2,3)$ from the distal electrodes (Color figure online) 


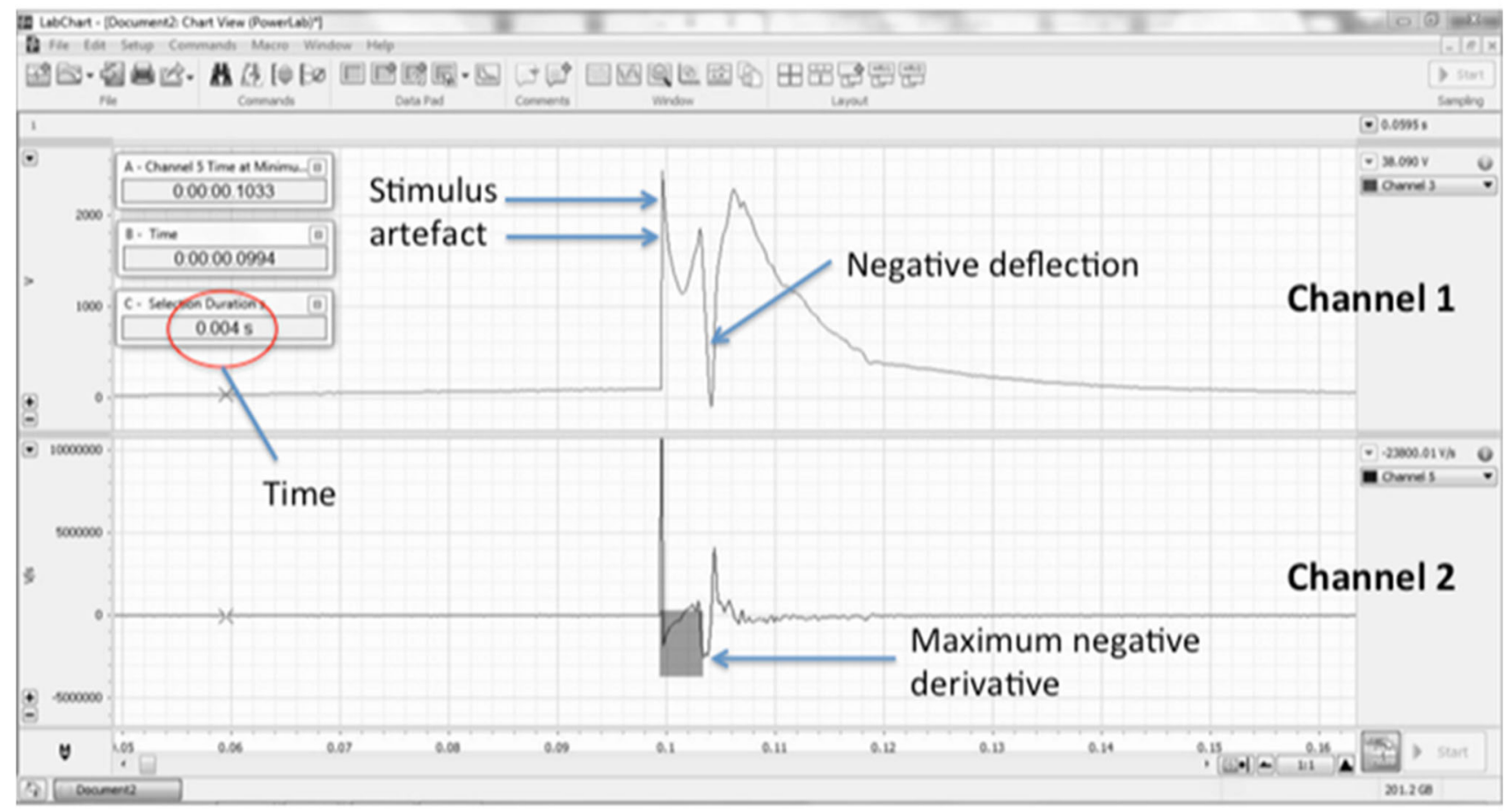

Fig. 2 Measurement of activation time. In Channel 1, the UEGM is shown with stimulus artefact and negative deflection. Channel 2 displays the first derivative of Channel 1 . AT is measured from the stimulus artefact to the maximum negative derivative (grey shaded area). This time is shown in the red circle (Color figure online)
Table 1 Baseline values for atrial and ventricular ERP, CV and LAT

\begin{tabular}{|c|c|c|c|c|c|c|}
\hline Variable & $n$ & Mean & SD & 25 th centile & Median & 75th centile \\
\hline Atrial ERP (ms) & 28 & 43.04 & 12.87 & 31.5 & 39 & 53.5 \\
\hline Ventricular ERP (ms) & 53 & 55.96 & 21.36 & 38 & 56 & 66 \\
\hline Atrial $\mathrm{CV}\left(\mathrm{cm} \mathrm{s}^{-1}\right)$ & 28 & 37.18 & 8.84 & 33.5 & 38 & 41 \\
\hline Ventricular $\mathrm{CV}\left(\mathrm{cm} \mathrm{s}^{-1}\right)$ & 36 & 53.94 & 27.27 & 35.5 & 48 & 59 \\
\hline Atrial LAT (ms) & 28 & 0.63 & 0.18 & 0.5 & 0.6 & 0.75 \\
\hline Ventricular LAT (ms) & 36 & 1.94 & 1.01 & 1.3 & 1.8 & 2.2 \\
\hline
\end{tabular}

$n$ Number of samples parameter was lower for atrial tissue than ventricular, and these differences were highly significant: $p=0.004$ for ERP, $p=0.003$ for CV and $p<0.001$ for LAT. However, there was variability between individual experiments and in some smaller subsets of experiments, these differences were not apparent (see below).

\section{EP Parameters in LA and LV Myocardium in Control Conditions}

It is important to establish how stable the recordings are with time and this might indicate deterioration of the tissue. Thus, in a subset of experiments, we studied the stability of the measurements with time. As shown in Fig. 3 and taken together, the measured EP parameters (ERP, CV and LAT) were stable in both atrial and ventricular ex vivo myocardial preparations for at least $30 \mathrm{~min}$.

\section{Response of EP Parameters in LA and LV Myocardium to Changes in Temperature}

We next moved on to assess how the electrophysiology of tissue slices from atria and ventricles responded to temperature and the results of the thermal challenge experiments are shown in Fig. 4. Taken together, temperature had effects of reasonable magnitude on both ERP and LAT in both atrial and ventricular tissues, with shortening of ERP and LAT as temperature increases. CV however was not affected. 

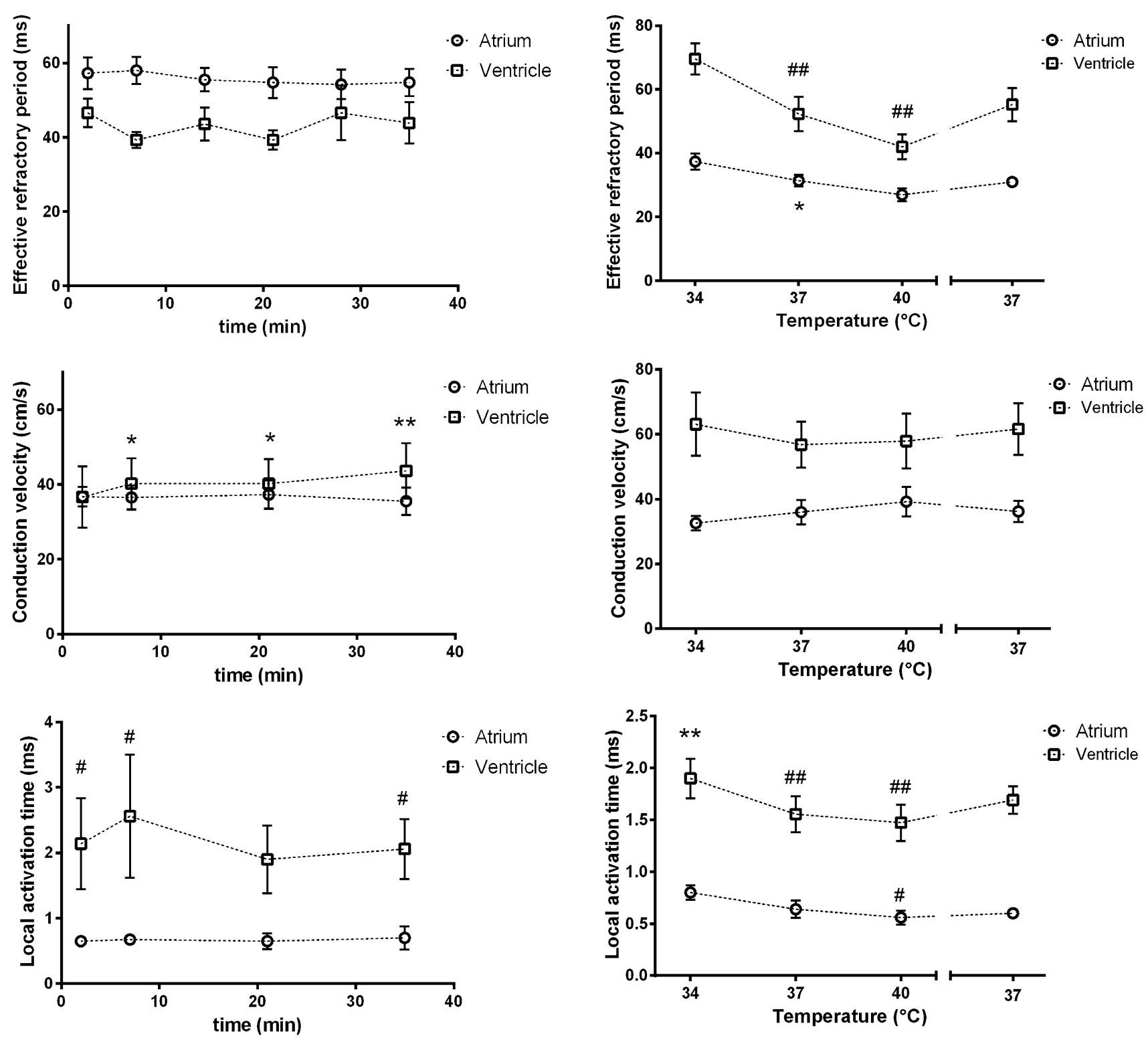

Fig. 3 Stability of measurements with time. There were no differences in ERP between groups at any time point during the protocol ( $n=4$ atria; $n=8$ ventricles). And compared to baseline, there were no differences at any time point for either group. For CV, there was no significant difference between groups at baseline $(p=0.985)$, nor at any time point ( $n=4$ atria; $n=5$ ventricles). Compared to baseline, atria did not differ at any time. Ventricles were significantly different at $7 \mathrm{~min}(+3.6 \mathrm{~cm} / \mathrm{s}, * p=0.028)$ and $21 \mathrm{~min}(+3.6 \mathrm{~cm} / \mathrm{s}$, $\left.{ }^{*} p=0.028\right)$, and highly significantly different at $35 \mathrm{~min}(+7 \mathrm{~cm} / \mathrm{s}$, $* * p<0.001)$. There were significant between-group differences in LAT at baseline $\left(\Delta 1.4 \mathrm{~ms},{ }^{\#} p=0.030\right)$, at $7 \mathrm{~min}(\Delta 1.89 \mathrm{~ms}$, $\left.{ }^{\#} p=0.006\right)$ and $35 \mathrm{~min}\left(\Delta 1.36 \mathrm{~ms},{ }^{\#} p=0.047\right) \quad(n=4$ atria; $n=5$ ventricles). Compared to baseline, there were no significant differences for either group at any time

Fig. 4 Response of EP parameters to temperature. Mean atrial ERP at $37^{\circ} \mathrm{C}$ was $31 \mathrm{~ms}$, and mean ventricular ERP was $52 \mathrm{~ms}$ $\left({ }^{*} p=0.015\right)$. Compared to $34^{\circ} \mathrm{C}$, atrial ERP was not significantly different at $37{ }^{\circ} \mathrm{C}$, though it approached significance at $40{ }^{\circ} \mathrm{C}$ $(p=0.058)$. Compared to $34^{\circ} \mathrm{C}$, ventricular ERP was highly significantly different at $37{ }^{\circ} \mathrm{C}$ and $40{ }^{\circ} \mathrm{C}(-17 \mathrm{~ms}$ and $-28 \mathrm{~ms}$, respectively, ${ }^{\# \#} p<0.001$ for both). At $37^{\circ} \mathrm{C}$, mean atrial $\mathrm{CV}$ was $36 \mathrm{~cm} / \mathrm{s}$, and mean ventricular $\mathrm{CV}$ was $57 \mathrm{~cm} / \mathrm{s} \quad(p=0.088)$. Compared to $34{ }^{\circ} \mathrm{C}$, there were no significant differences at 37 or $40{ }^{\circ} \mathrm{C}$ for either atria or ventricles. Mean atrial LAT at $37^{\circ} \mathrm{C}$ was $0.6 \mathrm{~ms}$, and mean ventricular LAT was $1.6 \mathrm{~ms} \quad(* * p<0.001)$. Compared to $34{ }^{\circ} \mathrm{C}$, atrial LAT did not differ significantly at $37{ }^{\circ} \mathrm{C}$, but did differ at $40{ }^{\circ} \mathrm{C}\left({ }^{\#} p=0.022\right)$. Ventricular LAT was highly significantly different at $37{ }^{\circ} \mathrm{C}$ and at $40{ }^{\circ} \mathrm{C}\left({ }^{\# \#} p<0.001\right.$ for both) 


\section{Response of EP Parameters in LA and LV} Myocardium to Muscarinic Receptor Agonist

We examined the changes of ERP, CV and LAT to challenge with a muscarinic receptor agonist namely carbachol. Overall, both atrial and ventricular tissues responded to
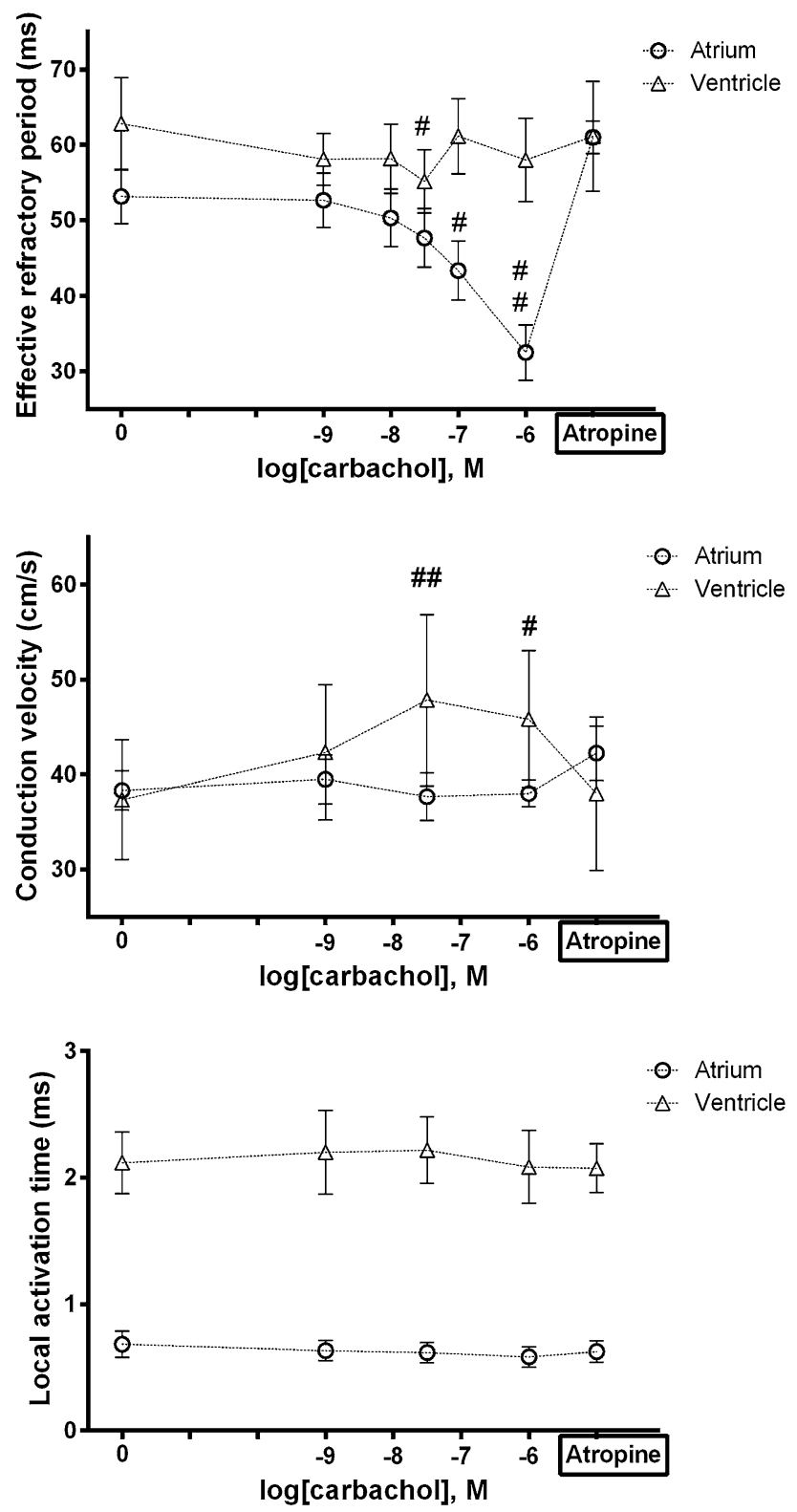

Fig. 5 Response of EP parameters to carbachol. Compared to baseline, atria had significantly shorter ERP at $10^{-7} \mathrm{M}(-10 \mathrm{~ms}$, $\left.{ }^{\#} p=0.042\right)$ and $10^{-6} \mathrm{M}$ carbachol $\left(-21 \mathrm{~ms},{ }^{\#} p<0.001\right)$. For ventricles, ERP was significantly shorter at $3 \times 10^{-8} \mathrm{M}(-8 \mathrm{~ms}$, $\left.{ }^{\#} p=0.032\right)$, but did not differ at any other concentrations. Compared to baseline, ventricular $\mathrm{CV}$ was highly significantly faster at $3 \times 10^{-8}$ $\mathrm{M}\left(+11 \mathrm{~cm} / \mathrm{s},{ }^{\# \#} p=0.001\right)$ and at $10^{-6} \mathrm{M}\left(+8.5 \mathrm{~cm} / \mathrm{s},{ }^{\#} p=0.009\right)$. There were no differences for atrial CVs. Compared to baseline, there were no significant changes for either chamber in LAT at any concentration of carbachol muscarinic agonists, yet in a different manner (Fig. 5): carbachol had no effect on ERP in the ventricle, whereas it modestly but significantly increased $\mathrm{CV}$ in this chamber. Conversely, in the atrium it had a large effect on ERP but no effect on $\mathrm{CV}$.

\section{Response of EP Parameters in LA and LV Myocardium to Beta-Adrenergic Receptor Agonist}

We examined the changes of ERP, CV and LAT to challenge with a b-adrenergic receptor agonist namely isoprenaline. Taken together, isoprenaline had interesting opposing effects on atrial and ventricular ERP, with a shortening of ERP in atrial and prolongation in ventricular slices (Fig. 6). Isoprenaline did not have any impact on CV in either cardiac chamber but had slight effects on ventricular LAT.

\section{Response of EP Parameters in LA and LV Myocardium to a Class I Anti-arrhythmic Drug}

Finally, we used a well-established pharmacological agent that should have predictable effects on tissue electrophysiology (Fig. 7). Overall, mexiletine affected both atrial and ventricular EP parameters in a similar manner, resulting in an expected increase in ERP and LAT, and decrease in CV.

\section{Discussion}

Arrhythmias are a major cause of morbidity and mortality. Currently, drugs, ablation and implantable cardioverter defibrillators are the mainstays of treatment. Although there are similarities in the mechanisms of atrial and ventricular arrhythmias, differences in anatomy and ion channel expression exist, and are potentially exploitable in terms of therapies. The autonomic nervous system has been implicated in initiating arrhythmias, yet our understanding of its effects on cardiac electrophysiology is far from complete.

While single-cell studies have been critical in understanding ion channel physiology, their value in electrophysiological modelling is limited by their lack of intercellular connections. Cardiac tissue slices have been used since the early 1990s to study tissue-level properties (Burnashev et al. 1991). The first study of adult murine heart slices with the MEA was reported in 2006 (Halbach et al. 2006), and adult human slices in 2011 (Camelliti et al. 2011). Several sections can be obtained from the same heart, with relative ease of perfusion and oxygenation. Importantly, tissue structure is maintained within the slice, yet the thinness means propagation can be studied in a pseudo-2D manner. 

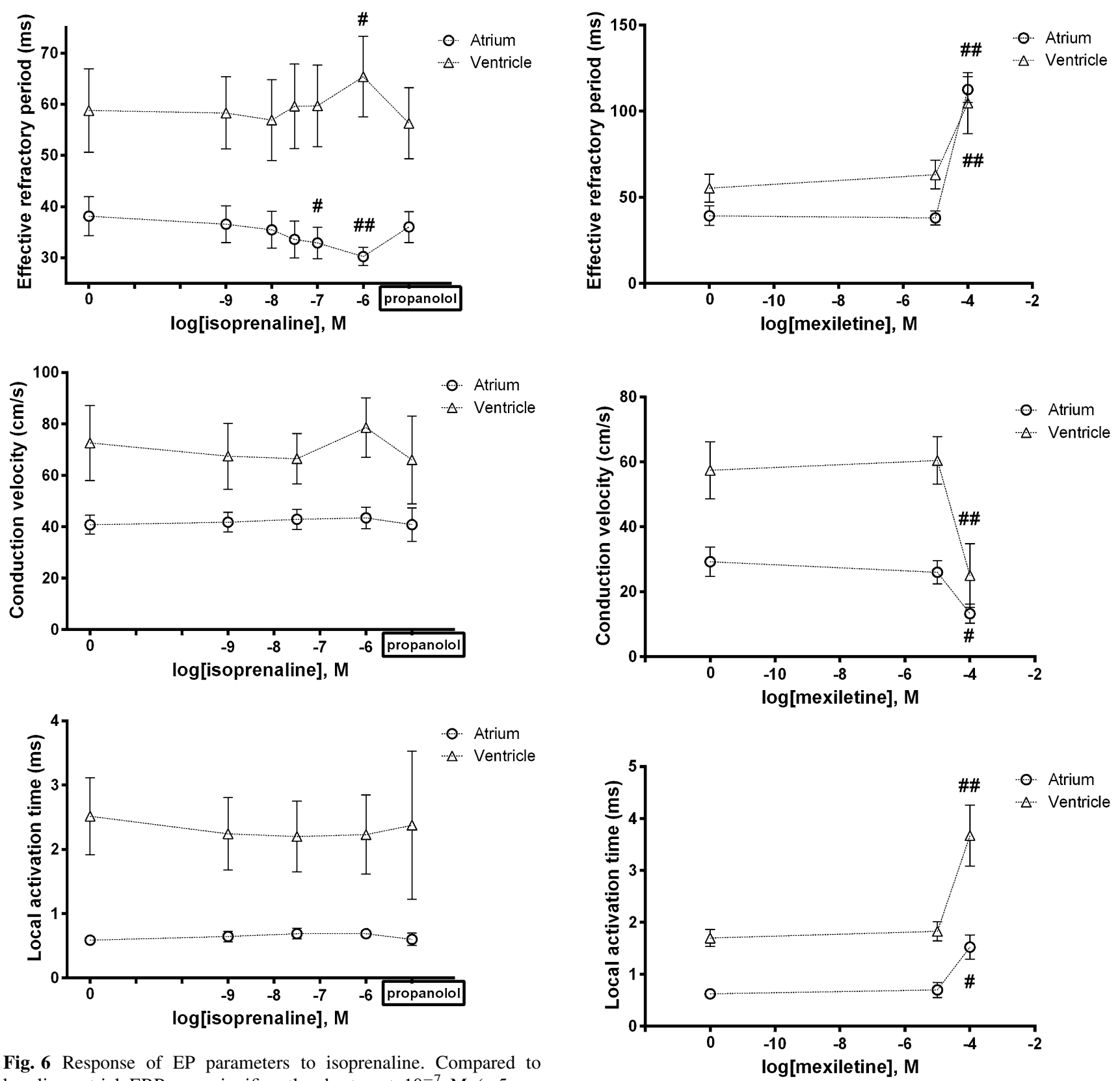

Fig. 6 Response of EP parameters to isoprenaline. Compared to baseline, atrial ERP was significantly shorter at $10^{-7} \mathrm{M}(-5 \mathrm{~ms}$, $\left.{ }^{\#} p=0.028\right)$ and $10^{-6} \mathrm{M}$ isoprenaline $\left(-8 \mathrm{~ms},{ }^{\#} p=0.001\right)$; in contrast, ventricular ERP was highly significantly longer at $10^{-6} \mathrm{M}$ only $\left(+7 \mathrm{~ms},{ }^{\#} p=0.004\right)$. There were no significant differences in $\mathrm{CV}$ with isoprenaline, compared to baseline, for either chamber. And neither were there any differences for atrial LAT at any concentration. For ventricles, however, there were small but significant reductions compared to baseline at each concentration

\section{Accuracy of Measurements and Chamber Differences}

Measured values of ERP, CV and AT were in the expected ranges (see Table 1). For example, Zuberi et al. found murine ventricular ERP to be $38 \mathrm{~ms}$, and Lerner et al. reported a value of $55 \mathrm{~ms}$ (Lerner et al. 2000; Zuberi et al.

Fig. 7 Response of EP parameters to mexiletine. Compared to baseline, there were no differences in ERP at $10^{-5} \mathrm{M}$ mexiletine for either chamber, though there were highly significant differences $\left({ }^{\# \#} p<0.001\right)$ for both atria and ventricles at $10^{-4} \mathrm{M}(+73 \mathrm{~ms}$ and $+49 \mathrm{~ms}$, respectively). And there were no differences in $\mathrm{CV}$ for either group at $10^{-5} \mathrm{M}$ compared to baseline, but at $10^{-4} \mathrm{M}$ atrial $\mathrm{CV}$ was significantly lower $\left(-16 \mathrm{~cm} / \mathrm{s},{ }^{*} p=0.019\right)$, and ventricular $\mathrm{CV}$ was highly significantly lower $\left(-32 \mathrm{~cm} / \mathrm{s},{ }^{\# \#} p<0.001\right)$. There was no difference at $10^{-5} \mathrm{M}$ mexiletine compared to baseline, in either atrial or ventricular LAT. But atrial LAT was significantly longer at $10^{-4} \mathrm{M}$ $\left(+0.9 \mathrm{~ms},{ }^{\#} p=0.017\right)$ and ventricular LAT was highly significantly longer $\left(+2.0 \mathrm{~ms},{ }^{\#} p<0.001\right)$

2010). Using murine hearts perfused with a voltage-sensitive fluorescent dye, Morley et al. found conduction velocities in the range of $30-65 \mathrm{~cm} \mathrm{~s}^{-1}$ (Morley et al. 
1999). And Kanai and Salama found LATs of 0-3 ms using guinea pig hearts (Kanai and Salama 1995). Comparison of baseline values across all the experiments revealed highly significant differences between atrial and ventricular tissue for each parameter, with atrial tissue having lower values for all. Such differences were seen in some but not all of the comparisons in individual experiments. It is likely that the larger number of measurements in combined data resulted in greater statistical power to detect differences.

A potential criticism of the study is that 'horizontal transverse' or short-axis ventricular slices were used, and myofibre orientation was not delineated in either ventricular nor atrial tissue. The relevance of this is that anisotropy is a well-recognised feature of cardiac conduction, with conduction velocity faster along the long axis compared to transversely across myofibres. Slicing in an alternate plane, to permit stimulation and recording along the long axis of fibres may have resulted in lower variation in ventricular conduction velocities in particular. Also, linear conduction was assumed, though this is almost certainly a simplification of the conduction path. However, we were interested in changes in parameters, rather than absolute values; and this assumption would not have affected measurements of ERP or LAT.

Chamber differences in ERP are fairly well established, at least in larger mammals. Compared with the ventricular action potential, the atrial action potential has a less negative resting potential, an abbreviated plateau phase and slower terminal repolarisation (Fatkin et al. 2007). These differences are predominantly due to increased $I_{\text {to }}$ and $I_{\text {Kur }}$ currents, as well as decreased $I_{\mathrm{K} 1}$ current (Fatkin et al. 2007; Koumi et al. 1995), and result in a shorter ERP in atria compared to ventricles. The differences in conduction velocity and activation time may well be accounted for by the differences in connexin expression; in the ventricle being largely $\mathrm{Cx} 43$ while in the atria, there is significant expression of $\mathrm{Cx} 40$ with $\mathrm{Cx} 43$ (Lambiase and Tinker 2015). Cx40 expression has been shown to be inversely associated with atrial conduction velocity (Kanagaratnam et al. 2002).

\section{Recording Stability and Response}

Parameters measured under control conditions without pharmacological or thermal challenge, were stable over $35 \mathrm{~min}$. Ventricular CV did increase significantly, though the magnitude of change was fairly small, $(+7 \mathrm{~cm} / \mathrm{s}$, $p<0.001$ ), equivalent to approximately $16 \%$ difference between beginning and end. One possibility for this is a 'warm-up' effect, as BDM was fully washed out of the tissue, with restoration of near-normal cellular physiology. In particular, the two main protein complexes involved in impulse propagation, the sodium channel and gap junction complexes, may take longer to recover than other channels.

To assess the responsiveness of the MEA system and its ability to report changes in EP parameters, the sodium channel blocker mexiletine was used. At a concentration of $10^{-4} \mathrm{M}$, there were significant increases in ERP and LAT, and significant decreases in CV for both atria and ventricles. While myocyte activation may be considered primarily dependent on $I_{\mathrm{Na}}$, with $\mathrm{CV}$ dependent on $I_{\mathrm{Na}}$ and gap junction conductance, ERP is usually thought to depend on repolarising currents. However, the increases in ERP seen with mexiletine, a pure sodium channel blocker, are probably explained by its preventing re-opening of the sodium channels even after full repolarisation, rather than through effects on the latter. This slowing of the reactivation of sodium channels that normally occurs with repolarisation, prolongs refractoriness independent of action potential duration (APD), which either shortens or remains unchanged with mexiletine (Darbar 2014; Tamargo and Delpon 2014).

\section{Autonomic Agonists}

Atrial ERP shortened with increasing concentration of carbachol, an expected finding likely attributable to activation of $I_{\mathrm{KACh}}$. In the ventricles, ERP was significantly shorter at $3 \times 10^{-8} \mathrm{M}$, but not at other concentrations. Whether this represents a real effect, or a statistical aberration is difficult to know. It is not concordant with the effects of vagal stimulation in the dog, for example, where lengthening of ventricular ERP occurs (Martins and Zipes 1980). $I_{\text {KACh }}$ and the corresponding channel subunits (GIRK1 and GIRK4) are thought to be expressed at lower levels in the ventricle (Dobrzynski et al. 2001), so muscarinic agonism would not be expected to prominently alter ventricular ERP in this way. Alternatively, there is evidence to support the idea that $\mathrm{G} \alpha_{\mathrm{i} 2}$ negatively regulates the L-type calcium channel (Chen et al. 2001; Nagata et al. 2000; Zuberi et al. 2010). A reduction in $\mathrm{Ca}^{2+}$ inflow could therefore shorten APD and ERP (Xiao et al. 1999).

Atrial CV did not vary with carbachol, whereas ventricular CV increased. Whether this latter effect reflects a similar process to that occurring in the control experiments, e.g. related to washout of BDM, is unclear. While it is possible that muscarinic signalling exerts effects on $I_{\mathrm{Na}}$ and thus CV, the absence of effects on LAT for either chamber suggests that this was not the case. Another possibility is that it exerts differential effects on gap junctions, which display some chamber specificity, as described above (Bukauskas 2014; Kléber 2014). More likely, therefore, it would seem to be a type I error.

Isoprenaline had divergent effects on atrial and ventricular ERP. There was a small reduction in atrial ERP, 
consistent with previous reports (Kim et al. 2012; Olshansky 2005). However, ventricular ERP lengthened slightly, an unexpected finding. For example, Martins et al. showed that in the canine ventricle, ERP shortened in response to sympathetic stimulation, and conversely, sympathetic denervation led to prolongation of ERP (Martins and Zipes 1980). And in humans, the effects are well described, and attributed largely if not wholly to phosphorylation of $I_{\mathrm{Ks}}$ by protein kinase A (PKA) (Vaseghi and Shivkumar 2008). The resultant increase in $\mathrm{K}^{+}$efflux leads to APD shortening, reflected in the normal reduction in QT interval that occurs with exercise. However, repolarisation in rodents is very different to that in large animals: $I_{\mathrm{Ks}}$ is not present in the mouse, and the main murine repolarising currents $I_{\mathrm{to}}, I_{\mathrm{Kslow} 1}, I_{\mathrm{Kslow} 2}$ and $I_{\mathrm{SS}}$, are less well studied. In the absence of a $\beta A R$-driven increase in $\mathrm{K}^{+}$outflow, $\beta \mathrm{AR}$ agonism may have resulted in an unopposed increase $\mathrm{Ca}^{2+}$ inflow producing a prolongation of APD and ERP.

There were no effects of isoprenaline on CV for either chamber, and while there was a small effect on ventricular LAT, no change was seen for atrial LAT. Published data generally support the idea that $\beta A R$ signalling increases $I_{\mathrm{Na}}$, via PKA-mediated phosphorylation (Campbell et al. 2014). However, there is not complete agreement (Grant 2009). In terms of functional effects, Lang et al. recently reported that both $\beta 1 \mathrm{AR}$ and $\beta 2 \mathrm{AR}$ agonism increased conduction velocity in human cardiac wedge preparations (Lang et al. 2015). And in a review on the subject, Campbell et al. found $\mathrm{CV}$ to be increased with $\beta \mathrm{AR}$ stimulation in intact hearts (Campbell et al. 2014). Mechanistically, they suggest that due to the non-linear relationship between $\mathrm{d} V / \mathrm{d} t_{\max }$ of phase 0 (an $I_{\mathrm{Na}}$-driven process) and conduction velocity, $\beta$ AR modulation of gap junction function may also be important, as suggested by previous reports (Burt and Spray 1988). However, most of the work investigating this has been carried out with neonatal cell preparations, without assessment of the effects on conduction. Finally, there may be murine strain differences as in preliminary studies in C57\Black6 mice; we do see an increase (Finlay and Tinker unpublished). This is a topic that needs wider investigation.

\section{Effects of Temperature on Electrophysiology}

Temperature modulation had significant effects of modest to large magnitude on both atrial and ventricular parameters. There was a small, non-significant negative relationship between ERP and temperature for atria, whereas for ventricles, there was a highly significant reduction of large magnitude. CV did not vary with temperature, whereas LAT showed similar patterns to ERP, with a modest negative relationship for atria, and a larger magnitude change for ventricles. Temperature's relationship with ERP is well studied, and our results are in keeping with previously published work. Spear et al. showed prolongation of activation-recovery intervals with lower temperatures (Spear and Moore 1998), and Coronel et al. found a negative relationship between temperature and monophasic action potential duration in isolated pig hearts (Coronel et al. 2006). Repolarising currents have been shown to exhibit temperature dependence: Kiyosue et al. showed that in guinea pig ventricular myocytes, $I_{\mathrm{K}}$ was reduced at lower temperatures, and that APD was prolonged (Kiyosue et al. 1993).

The lack of change of CV with temperature was surprising given the reported association. Smeets et al. found an increase in CV with higher temperatures in rabbit atria (Smeets et al. 1986), and Morley et al. found reduction in velocities in mice between 37 and $25{ }^{\circ} \mathrm{C}$ (Morley et al. 1999). Two obvious explanations for the results exist. The first is that the temperature range studied was too narrow, and centred around $37^{\circ} \mathrm{C}$. In contrast, the two studies mentioned above had a maximum temperature of $37{ }^{\circ} \mathrm{C}$ and a minimum of $25-27^{\circ} \mathrm{C}$. This narrow temperature range was chosen deliberately, as both upper and lower temperatures are quite possible in humans, yet far enough from 'normal' to in theory at least, elicit changes. Oddly though, there was not even a non-significant trend, with $\mathrm{CV}$ at $34{ }^{\circ} \mathrm{C}$ slightly higher than at $37{ }^{\circ} \mathrm{C}$. The second possibility is that murine conduction does not vary so easily with temperature as it does in the rabbit. Finally, the relationship between LAT and temperature is supported by previous experimental work with isolated perfused rabbit hearts (Spear and Moore 1998) and frog ventricular fibres (Hecht 1957). This parameter is dependent on $I_{\mathrm{Na}}$, and experimental support for the temperature dependence of sodium channel conductance has come from patch-clamp work using rat ventricular myocytes (Milburn et al. 1995).

The importance of temperature in arrhythmogenicity is best exemplified by Brugada syndrome, where fever can trigger ventricular arrhythmias. Dumaine et al. demonstrated a molecular mechanism for the SCN5A gene Thr1620Met mutation. They found that current decay kinetics and recovery from inactivation of the channel was altered compared to the wild-type channel (Dumaine et al. 1999). Hypothermia has also been implicated as an arrhythmic trigger, but in the setting of early repolarisation syndrome (Bastiaenen et al. 2010). Although not investigated in this study, arrhythmic triggers are clearly also important. In this regard, Mugelli et al. reported increased after potentials when myocardial temperature is raised from 34 to $37{ }^{\circ} \mathrm{C}$ (Mugelli et al. 1986); this was investigated in the context of reperfusion arrhythmias following ischaemia. 


\section{Limitations and Future Directions}

We did not check for ischaemia or markers of cell death in the tissue slices, though our technical approach was designed to minimise this, and we closely followed protocols from Camilliti and colleagues who found no evidence for this $\{$ ref $\}$. There are a number of interesting possibilities to extend this work. It would be revealing to investigate regional differences in tissue electrophysiology to adapt our methods to compare basal and apical electrophysiology though this was not possible in the current study. It might also be possible to adapt these approaches to study the electrophysiological effects of pathophysiological responses such as ischaemic preconditioning.

\section{Conclusions}

In summary, we have used a multielectrode array system to investigate chamber differences in three important EP parameters, and their responses to autonomic and thermal modulation. The system produced reliable measurements, and was able to report robust changes such as those induced by mexiletine. However, there was some variability between mice and individual preparations. We have demonstrated significant differences in ERP, CV and LAT between atrial and ventricular tissue at baseline. Responses to autonomic agonists may to some degree reflect species differences in signalling and ionic currents, and temperature was shown to have important effects on ERP and LAT.

Acknowledgements This work was supported by the British Heart Foundation (FS/12/11/29289), The National Institute for Health Research Barts Cardiovascular Biomedical Research Unit, BHF programme Grant (RG/15/15/31742) and the Fédération Française de Cardiologie et Fondation Coeur et Artères.

\section{Compliance with Ethical Standards}

Conflict of interest The authors have no conflicts of interest to declare.

Ethical Approval All applicable international, national and/or institutional guidelines for the care and use of animals were followed. This article does not contain any studies with human participants performed by any of the authors.

Open Access This article is distributed under the terms of the Creative Commons Attribution 4.0 International License (http://crea tivecommons.org/licenses/by/4.0/), which permits unrestricted use, distribution, and reproduction in any medium, provided you give appropriate credit to the original author(s) and the source, provide a link to the Creative Commons license, and indicate if changes were made.

\section{References}

Bastiaenen R, Hedley PL, Christiansen M, Behr ER (2010) Therapeutic hypothermia and ventricular fibrillation storm in early repolarization syndrome. Heart Rhythm 7(6):832-834. doi:10. 1016/j.hrthm.2010.02.037

Bukauskas FF (2014) Molecular organization, gating, and function of gap junction channels. In: Zipes DP, Jalife J (eds) Cardiac electrophysiology from cell to bedside, 6th edn. Elsevier Saunders, Philadelphia, pp 85-94

Burnashev NA, Edwards FA, Verkhratskii AN (1991) The use of thin slices of myocardium for recording the currents across single ion channels. Fiziologicheskiǐ Zhurnal 37:119-122

Burt JM, Spray DC (1988) Inotropic agents modulate gap junctional conductance between cardiac myocytes. Am J Physiol 254(6 Pt 2):H1206-H1210

Bussek A, Wettwer E, Christ T, Lohmann H, Camelliti P, Ravens U (2009) Tissue slices from adult mammalian hearts as a model for pharmacological drug testing. Cell Physiol Biochem 24:527-536

Camelliti P, Al-Saud SA, Smolenski RT, Al-Ayoubi S, Bussek A, Wettwer E et al (2011) Adult human heart slices are a multicellular system suitable for electrophysiological and pharmacological studies. J Mol Cell Cardiol 51(3):390-398. doi:10. 1016/j.yjmcc.2011.06.018

Campbell AS, Johnstone SR, Baillie GS, Smith G (2014) $\beta$ Adrenergic modulation of myocardial conduction velocity: connexins vs. sodium current. J Mol Cell Cardiol 77:147-154. doi:10.1016/j.yjmcc.2014.09.030

Chen F, Spicher K, Jiang M, Birnbaumer L, Wetzel GT (2001) Lack of muscarinic regulation of $\mathrm{Ca}^{2+}$ channels in $\mathrm{Gi} 2 \alpha$ gene knockout mouse hearts. Am J Physiol 280:H1989-H1995

Coraboeuf E, Weidmann S (1949) Potentiels d'action du muscle cardiaque obtenus à l'aide de microélectrodes intracellulaires. C R Séances Soc Biol 143:1360

Coronel R, de Bakker JMT, Wilms-Schopman FJG, Opthof T, Linnenbank AC, Belterman CN, Janse MJ (2006) Monophasic action potentials and activation recovery intervals as measures of ventricular action potential duration: experimental evidence to resolve some controversies. Heart Rhythm 3(9):1043-1050. doi:10.1016/j.hrthm.2006.05.027

Darbar D (2014) Standard antiarrhythmic drugs. In: Zipes D, Jalife J (eds) Cardiac electrophysiology from cell to bedside, 6th edn. Elsevier Saunders, Philadelphia, pp 1095-1108

Dobrzynski H, Marples DD, Musa H, Yamanushi TT, Henderson Z, Takagishi $Y$ et al (2001) Distribution of the muscarinic $\mathrm{K}+$ channel proteins Kir3.1 and Kir3.4 in the ventricle, atrium, and sinoatrial node of heart. $\mathbf{J}$ Histochem Cytochem 49(10):1221-1234. doi:10.1177/002215540104901004

Dumaine R, Towbin JA, Brugada P, Vatta M, Nesterenko DV, Nesterenko VV et al (1999) Ionic mechanisms responsible for the electrocardiographic phenotype of the Brugada syndrome are temperature dependent. Circ Res 85(9):803-809. doi:10.1161/ 01.RES.85.9.803

Fatkin D, Otway R, Vandenberg J (2007) Genes and atrial fibrillation: a new look at an old problem. Circulation 116(7):782-792

Giles WR, Imaizumi Y (1988) Comparison of potassium currents in rabbit atrial and ventricular cells. J Physiol 405:123-145. doi:10. 1113/jphysiol.1988.sp017325

Grant AO (2009) Cardiac ion channels. Circ Arrhythm Electrophysiol 2(2):185-194. doi:10.1161/CIRCEP.108.789081

Halbach M, Pillekamp F, Brockmeier K, Hescheler J, Müller-Ehmsen J, Reppel M (2006) Ventricular slices of adult mouse hearts-a new multicellular in vitro model for electro-physiological studies. Cell Physiol Biochem 18:1-8 
Hecht HH (1957) Normal and abnormal transmembrane potentials of the spontaneously beating heart. Ann N Y Acad Sci 65:700-733

Janse MJ, Rosen MR (2006) History of arrhythmias. Handb Exp Pharmacol 171:1-39

Kanagaratnam P, Rothery S, Patel P, Severs NJ, Peters NS (2002) Relative expression of immunolocalized connexins 40 and 43 correlates with human atrial conduction properties. J Am Coll Cardiol 38:116-123

Kanai A, Salama G (1995) Optical mapping reveals that repolarization spreads anisotropically and is guided by fiber orientation in guinea pig hearts. Circ Res 77:784-802

Kim S, Zhang H, Khaliulin I, Choisy S, Bond R, Lin H et al (2012) Activation of glibenclamide-sensitive ATP-sensitive $\mathrm{K}+$ channels during $\beta$-adrenergically induced metabolic stress produces a substrate for atrial tachyarrhythmia. Circ Arrhythm Electrophysiol 5(6):1184-1192

Kiyosue T, Arita M, Muramatsu H, Spindler AJ, Noble D (1993) Ionic mechanisms of action potential prolongation at low temperature in guinea-pig ventricular myocytes. J Physiol 468:85-106

Kléber AG (2014) Intercellular communication and impulse propagation. In: Zipes D, Jalife J (eds) Cardiac electrophysiology from cell to bedside, 6th edn. Elsevier Saunders, Philadelphia, pp 265-275

Koumi S, Backer C, Arentzen C (1995) Characterization of inwardly rectifying $\mathrm{K}^{+}$channel in human cardiac myocytes. Alterations in channel behavior in myocytes isolated from patients with idiopathic dilated cardiomyopathy. Circulation 92(2):164-174

Lambiase PD, Tinker A (2015) Connexins in the heart. Cell Tissue Res 360:675-684. doi:10.1007/978-1-59745-489-6_21

Lang D, Holzem K, Kang C, Xiao M, Hwang HJ, Ewald GA et al (2015) Arrhythmogenic remodeling of $\beta 2$ versus $\beta 1$ adrenergic signaling in the human failing heart. Circ Arrhythm Electrophysiol. doi:10.1161/CIRCEP.114.002065

Lerner DL, Yamada KA, Schuessler RB, Saffitz JE (2000) Accelerated onset and increased incidence of ventricular arrhythmias induced by ischemia in $\mathrm{Cx} 43$-deficient mice. Circulation 101(5):547-552. doi:10.1161/01.CIR.101.5.547

Ling G, Gerard RW (1949) The normal membrane potential of frog Sartorius fibers. J Cell Comp Physiol 34:383

Martins JB, Zipes DP (1980) Effects of sympathetic and vagal nerves on recovery properties of the endocardium and epicardium of the canine left ventricle. Circ Res 46:100-110. doi:10.1161/01.RES. 46.1.100

Milburn T, Saint DA, Chung SH (1995) The temperature dependence of conductance of the sodium channel: implications for mechanisms of ion permeation. Receptors Channels 3(3):201-211
Morley GE, Vaidya D, Samie FH, Lo C, Delmar M, Jalife J (1999) Characterization of conduction in the ventricles of normal and heterozygous $\mathrm{Cx} 43$ knockout mice using optical mapping. J Cardiovasc Electrophysiol 10:1361-1375

Mugelli A, Cerbai E, Amerini S, Visentin S (1986) The role of temperature on the development of oscillatory afterpotentials and triggered activity. J Mol Cell Cardiol 18(12):1313-1316

Nagata K, Ye C, Jain M, Milstone DS, Liao R, Mortensen RM (2000) $\mathrm{G} \alpha \mathrm{i} 2$ but not $\mathrm{G} \alpha \mathrm{i} 3$ Is required for muscarinic inhibition of contractility and calcium currents in adult cardiomyocytes. Circ Res 87(10):903-909. doi:10.1161/01.RES.87.10.903

Olshansky B (2005) Interrelationships between the autonomic nervous system and atrial fibrillation. Prog Cardiovasc Dis 48(1):57-78

Opel A, Nobles M, Montaigne D, Finlay M, Anderson N, Breckenridge R, Tinker A (2015) Absence of the regulator of G-protein signaling, RGS4, predisposes to atrial fibrillation and is associated with abnormal calcium handling. J Biol Chem 290(31):19233-19244. doi:10.1074/jbc.M115.666719

Pillekamp F, Reppel M, Dinkelacker V, Duan Y, Jazmati N, Bloch W et al (2005) Establishment and characterization of a mouse embryonic heart slice preparation. Cell Physiol Biochem 16(1-3):127-132. doi:10.1159/000087739

Shen MJ, Zipes DP (2014) Role of the autonomic nervous system in modulating cardiac arrhythmias. Circ Res 114(6):1004-1021. doi:10.1161/CIRCRESAHA.113.302549

Smeets JLRM, Allessie MA, Lammers WJEP, Bonke FIM, Hollen J (1986) The wavelength of the cardiac impulse and reentrant arrhythmias in isolated rabbit atrium. Circ Res 58:96-108

Spear JF, Moore EN (1998) Modulation of quinidine-induced arrhythmias by temperature in perfused rabbit heart. Am J Physiol 274:817-828

Tamargo J, Delpon E (2014) Pharmacologic bases of antiarrhythmic therapy. In: Zipes D, Jalife J (eds) Cardiac electrophysiology from cell to bedside, 6th edn. Elsevier Saunders, Philadelphia, pp 529-540

Vaseghi M, Shivkumar K (2008) The role of the autonomic nervous system in sudden cardiac death. Prog Cardiovasc Dis 50(6):404-419. doi:10.1016/j.pcad.2008.01.003

Xiao R-P, Avdonin P, Zhou Y-Y, Cheng H, Akhter SA, Eschenhagen $\mathrm{T}$ et al (1999) Coupling of beta 2-adrenoceptor to Gi proteins and its physiological relevance in murine cardiac myocytes. Circ Res 84(1):43-52. doi:10.1161/01.RES.84.1.43

Zuberi Z, Nobles M, Sebastian S, Dyson A, Lim SY, Breckenridge R et al (2010) Absence of the inhibitory G-protein Galphai2 predisposes to ventricular cardiac arrhythmia. Circ Arrhythm Electrophysiol 3(4):391-400. doi:10.1161/CIRCEP.109.894329 